\title{
Adjuvant chemotherapy for peritoneal cytology- positive stage IA endometrial cancer
}

\section{Motoko Kanno}

The Cancer Institute Hospital

Mayu Yunokawa ( $\square$ mayu.yunokawa@jfcr.or.jp )

The Cancer Institute Hospital

\section{Makoto Nakabayashi}

The Cancer Institute Hospital

\section{Makiko Omi}

The Cancer Institute Hospital

\section{Yuko Sugiyama}

The Cancer Institute Hospital

Nobuhiro Takeshima

The Cancer Institute Hospital Hiroyuki Kanao

The Cancer Institute Hospital Ai lkki

The Cancer Institute Hospital

\section{Megumi Mizusaki}

The Cancer Institute Hospital

\section{Mai Nishimura}

The Cancer Institute Hospital

\section{Kouta Okamoto}

The Cancer Institute Hospital

\section{Yuji Tanaka}

The Cancer Institute Hospital

\section{Atsushi Fusegi}

The Cancer Institute Hospital

\section{Sachiho Netsu}

The Cancer Institute Hospital

\section{Tomoko Kurita}

The Cancer Institute Hospital

\section{Yoichi Aoki}

The Cancer Institute Hospital 
The Cancer Institute Hospital

\section{Maki Matoda}

The Cancer Institute Hospital

\section{Sansiro Okamoto}

The Cancer Institute Hospital

\section{Hidetaka Nomura}

The Cancer Institute Hospital

\section{Kohei Omatsu}

The Cancer Institute Hospital

\section{Kuniko Utsugi}

The Cancer Institute Hospital

\section{Yusuke Shimizu}

The Cancer Institute Hospital

\section{Research Article}

Keywords: peritoneal cytology, endometrial cancer, early stage, adjuvant chemotherapy

Posted Date: May 5th, 2021

DOl: https://doi.org/10.21203/rs.3.rs-460308/v1

License: (c) (1) This work is licensed under a Creative Commons Attribution 4.0 International License. Read Full License 


\section{Abstract \\ Purpose}

This study aimed at evaluating the influence of positive peritoneal cytology (PPC) on the prognosis of patients with stage IA endometrial cancer, and the usefulness of adjuvant chemotherapy in their treatment.

\section{Methods}

We retrospectively analyzed the data of patients with stage I A endometrial cancer admitted in our hospital between 2005 and 2015.

\section{Results}

Among 989 patients with stage IA endometrial cancer who underwent peritoneal cytology, 135 (13.7 \%) had PPC. In multivariate analysis, BMI $\geq 25 \mathrm{~kg} / \mathrm{m}^{2}$, grade 2 cancer, type II cancer, muscle invasion, and PPC were extracted as independent risk factors for recurrence in stage IA patients. In addition, type II cancer was identified as an independent risk factor in stage IA patients with PPC. There was no significant difference in the 5-year relapse-free survival rate in stage IA patients with PPC who received adjuvant chemotherapy when compared those who did not receive chemotherapy $(p=0.78)$. Similarly, the difference in the 5-year recurrence free survival rate between the two groups was not significant in patients with type II cancers $(p=0.11)$. However, the baseline risk of 5 -year relapse-free survival without chemotherapy in stage IA patients with PPC and type II was very low (66.7\%).

\section{Conclusions}

PPC was an independent risk factor for recurrence in stage IA endometrial cancer. Adjuvant chemotherapy did not influence the relapse-free survival rate in patients with stage IA endometrial cancer with PPC. Therefore, it is necessary to investigate adjuvant chemotherapy for early endometrial cancer patients with risk factors for recurrence, especially those with multiple factors.

\section{Introduction}

Endometrial cancer is the most common gynecological cancer in advanced countries and its prevalence is expected to further rise with time. Most patients are diagnosed in the early stage because symptoms of atypical genital bleeding develop in more than $90 \%$ of patients. When reported early, approximately 75 to $80 \%$ of endometrial cancer (EEC) patients are diagnosed at Federation of Gynecology and Obstetrics (FIGO) Stage I, and stage IA patients are known to have a favorable prognosis with a 5-year survival rate $\geq 90 \%(1,2)$. 
Positive peritoneal cytology (PPC) has been reported to be a poor prognostic factor for endometrial cancers, but it is not included the International FIGO 2009 stage classification. Studies show that PPC does not influence the prognosis of stage III cancers unlike other factors like lymph node metastasis, and uterine serosal or adnexal metastasis, but it is unclear whether PPC influences the prognosis in patients with early stage endometrial cancer(3-5). A Although some studies have reported PPC to be a risk factor for recurrence in patients with EEC, other studies have not found PPC to be an independent risk factor for occurrence. So, no consensus has been established(6-18).

Several guidelines recommend postoperative adjuvant therapy for EEC patients having risk factors for recurrence $(1,2)$. However, its efficacy, especially in stage IA EEC, is unclear.

The objective of this study was to evaluate the influence of potential independent risk factors like PPC on the prognosis of patients with stage IA EEC, and to evaluate the usefulness of postoperative adjuvant chemotherapy in its treatment.

\section{Material And Methods}

\subsection{Patient population}

This was a retrospective comparative study involving data on patients with endometrial cancer (FIGO stage IA) who received their first treatment at The Cancer Institute Hospital between January 2005 and December 2015. The study was approved by The Cancer Institute Hospital of JFCR Review Board and was conducted in accordance with the relevant guidelines and regulations of the Institutional Review Board. We obtained signed informed consent from participants. We excluded the following patients: those who died from another disease, those who had undergone a hysteroscopic examination before surgery, patients who received preoperative hormone therapy or chemotherapy, and patients who had multiple cancers (thus affecting the EEC treatment protocol) $(19,20)$.

\subsection{Study definition}

Surgical staging was performed using the FIGO 2009 staging system(21). According to this classification, an invasion of $<50 \%$ of the uterine muscle is classified as stage IA. Concerning the tumor grading, the World Health Organization (WHO) 2014 classification was used (22). Ages and body mass index (BMI) were each grouped into two categories (ages $<60$ and ages $\geq 60 ; \mathrm{BMI}<25$ and $\mathrm{BMl} \geq 25 \mathrm{~kg} / \mathrm{m}^{2}$, respectively) on the basis of the grouping done in previous studies $(23,24)$. A False PPC was classified as negative according to Japanese guidelines (2). The relapse-free survival time was defined as the time lapse between the first recurrence and the day of the surgery or (in patients without recurrence) the time lapse between the day of the surgery and last consultation (follow-up) day. The overall survival time was defined as the time lapse between the day of the surgery and the date of death or the last consultation day (for patients who were still alive). The patterns of recurrence included locoregional recurrences (defined as vaginal or intrapelvic recurrences) and distant recurrences (upper para-aortic lymph node metastasis, peritoneal dissemination, and metastasis to other organs). 


\subsection{Surgery and Adjuvant chemotherapy}

The basic surgical procedures used to treat EEC in our hospital included: total hysterectomy, bilateral salpingo-oophorectomy, and regional lymph node biopsy/dissection. Two types of hysterectomy procedures could be performed: simple total hysterectomy and modified radical hysterectomy. Omentectomy was performed in patients with non-endometrioid adenocarcinoma, or with PPC. Regional lymph node dissection was omitted (in some patients) when type I lymph node enlargement and uterine muscle invasion were absent on imaging diagnosis. Patients in whom a lymph node biopsy was performed without systematic dissection were grouped with patients without dissection. The choice between laparotomy and laparoscopy was made based on the size of the complicating uterine fibroids. Specimens for peritoneal fluid cytology were collected from the Douglas pouch by aspiration or washing at the initiation of surgery.

Adjuvant chemotherapy was administered if the patient had any one of the following risk factors: Type II EEC, vascular invasion, muscle invasion ( $<1 / 2)$, and PPC in patients with FIGO stage I (2). Six courses of chemotherapy were administered, and the regimens used were:

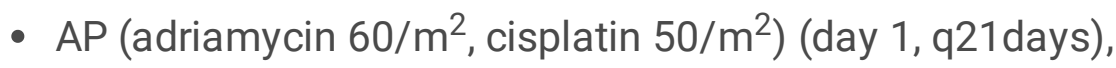

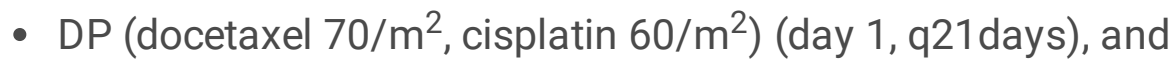

- TC (paclitaxel 175/ $\mathrm{m}^{2}$, carboplatin AUC =6) (day 1, q21days).

Patients who received three or more courses were included for analysis in this study (25).

\subsection{Statistical analysis}

Characteristics were compared using Fisher's exact test. For the analysis of the period of recurrence, Cox's regression analysis was used, and univariate and multivariate analyses were performed to identify the prognostic factors. The relapse-free survival curve and overall survival curve were prepared using the Kaplan-Meier method. P-values $<0.05$ were considered statistically significant. The hazard ratio and $95 \%$ confidence interval were calculated. The software Easy R (EZR) Version 1.38 was used for statistical analyses (26).

\subsection{Ethical approval and Consent for Participation and Consent for Publication}

Before participating in the study, all subjects gave their informed consent to participate in it. We conducted this study in accordance with the Declaration of Helsinki, and the protocol was accepted by the Ethics Committee of the Cancer Institute Ariake Hospital, JFCR (approval number, № 2018 - 1238).

\section{Results}

\section{Patients' characteristics}


In total, 1041 patients with stage IA endometrial cancer were admitted into our institution during the study period and 989 were eligible for inclusion in this study (Figure 1). The median age was 55 years (range: 26-87 years). The median duration of follow-up for all the patients was 70 months (range, 2-166 months). Out of the 989 patients who underwent peritoneal cytology, 135 patients (13.7\%) were positive (Fig. 1) (Table 1).

\section{Univariate and multivariate analysis for recurrence}

Univariate analysis was performed to identify the risk factors for recurrence (Table 2). In univariate analysis, the poor prognostic factors identified were age $\geq 60$ years, $\mathrm{BMI} \geq 25 \mathrm{Kg} / \mathrm{m}^{2}$, grade 2 cancer, type II cancer, PPC, muscle invasion, and lymphovascular space invasion. In multivariate analysis, BMI $\geq$ $25 \mathrm{~kg} / \mathrm{m}^{2}$, grade 2 cancer, type II cancer, muscle invasion, and PPC were extracted as independent risk factors for recurrence (Table 2).

The 5-year relapse-free survival rates were significantly lower in patients with PCC (96.2\% vs. 91.8\%, $\mathrm{p}=0.002$ ) (Supplementary Fig. 1).

There were 135 patients with PPC stage IA endometrial cancer (Table 3). In univariate analysis of stage IA EEC patients with PPC, the risk factors for recurrence were age $\geq 60$ years and type II cancer. In multivariate analysis, type II cancer was identified as an independent risk factor (Table 4).

The 5-year relapse-free survival rates were significantly lower in type II patients with stage IA EEC with PPC (97\% vs. $78.6 \%, p<0.001)$ (Supplementary Fig. 2).

\section{The efficacy of postoperative adjuvant chemotherapy}

In 135 patients with PPC, 13 (9.6\%) developed a recurrence. Out of the 58 patients who received adjuvant chemotherapy, 6 (10.3\%) developed recurrences (4 patients had distant metastases and 2 had local recurrences). Out of the 77 patients who did not receive adjuvant chemotherapy, 7 patients $(9.1 \%)$ developed recurrences ( 1 had a local recurrence and 6 had distant metastases).

For the stage IA EEC patients with PPC, there was no significant difference in the 5-year relapse-free survival rate between those who did not receive adjuvant chemotherapy and those who did received (93.5\% against $89.6 \%, p=0.78)$ (Fig. 2-1).

The relapse-free survival rates of patients with and without adjuvant chemotherapy were analyzed with the cancer type. In patients with type I cancer, there was no significant difference in the 5-year relapse-free survival rate between patients with and those without adjuvant chemotherapy (93.5\% against $97.1 \%$, 
$\mathrm{p}=0.70)($ Fig 2-2). Similarly, the difference between these two groups was not significant in patients with type II (85.2\% against $66.7 \%$, $p=0.11)$ (Fig. 2-3).

Also, in patients with type II cancer, there was no significantly difference in the 5-year overall survival rate between patients with and those without adjuvant chemotherapy ( $91.9 \%$ versus $77.8 \%, p=0.15)$

(Supplementary Fig. 3).

\section{Discussion}

This study found that PPC, alongside a BMI $\geq 25$, type Il cancer, muscle invasion, and grade 2 cancer, was an independent poor prognostic factor in patients with stage IA EEC. In stage IA EEC with PPC, type II cancer was the only independent poor prognostic factor. The administration of adjuvant chemotherapy was not associated with a longer relapse-free survival in all the stage IA EEC patients with PPC.

Several studies have reported that PPC is a risk factor for cancer recurrence in patients with EEC (stage I and II) after revision of the FIGO 2009 staging (6-15). In our study which focused on stage IA EEC, PPC was an independent risk factor for recurrence $(p=0.036)$. Wang et al. however reported that PPC does not influence the overall survival rate of patients with stage IA EEC (16). They excluded non-endometrioid cancers from their study and this could explain the difference in the findings. The European Society for Medical Oncology guidelines recommend the collection of peritoneal cytology information, especially in patients with tumors of non-endometrioid histology. This is because a retrospective study showed that PPC has a prognostic value (1). In the present study, PPC was a risk factor for recurrence in stage IA endometrial cancer, and it is necessary to carefully manage it.

Atypical cells in peritoneal cytology were considered negative on the basis of the Japanese guidelines (2). Matsuo et al. suggested that the presence of malignant cells or atypical cells on peritoneal cytology should be defined abnormal peritoneal cytology (14). Presently, we decided to create a cell block in case of atypical cells. The cell block method allows us to diagnose malignant cells by pathology. In the future, we need to examine the treatment of atypical cells, including their prognosis.

Matsuo et al. reported that adjuvant chemotherapy for PPC in EEC (stages I and II) may reduce the incidence of distant metastasis (14). Seagle et al. also reported that adjuvant chemotherapy increased the survival rate of EEC with PPC (stage I and II) patients (15). However, Wang et al. reported that adjuvant chemotherapy did not improve the outcome of PPC stage IA EEC (with endometrioid carcinoma) (16). In our study, adjuvant chemotherapy for IA EEC with PPC did not improve the relapse-free survival. The 5-year relapse-free survival rate of stage IA EEC patients with PPC without chemotherapy was $93.8 \%$ in the overall population. These results suggest that adjuvant chemotherapy was not always necessary for the all stage IA patients with PPC because the baseline risk for recurrence in these patients was very good in our study. We should select patients with higher risk for recurrence among stage IA EEC patients with PPC. 
In addition to advanced stage, high-grade endometrial carcinoma or non-endometrial carcinoma, defined as type II subtype and the presence of vascular and/or muscle invasion, have been reported as poor prognostic factors $(1,2,27)$. Melody, Tatebe, and Donovan et al. reported studies on stage IA serous adenocarcinoma and clear cell cancer among type II patients in which postoperative radiotherapy and chemotherapy prolonged the relapse-free survival $(28-30)$.

In our study, type II cancer was an independent risk factor for recurrence in stage IA EEC patients with PPC; therefore, we investigated the efficacy of adjuvant chemotherapy as a function to the cancer type. Adjuvant chemotherapy for type I patients (stage IA with PPC) did not improve the relapse-free survival with a good baseline risk (the 5-year relapse-free survival rate was 93.5\%). In addition, adjuvant chemotherapy for type II patients did not significantly improve relapse-free survival. However, the baseline risk of 5-year relapse-free survival without chemotherapy was very low $(66.7 \%)$. Although there was no significant difference, the 5 -year relapse-free survival rate of patients who received adjuvant chemotherapy with PPC stage IA type II EEC was $85.2 \%$. On the other hand, the 5-year relapse-free survival rate of patients who did not receive adjuvant chemotherapy is $66.7 \%$. Therefore, it may be better to treat them with adjuvant chemotherapy. Analyses involving a larger number of patients and prospective trials need to be carried out to ascertain the need for adjuvant chemotherapy in early stage patients with type II cancers. This lack of significant difference in our study could be due to the small sample size we used. More importantly, it is necessary to select treatment taking into consideration the risk for recurrence of individual factors because the baseline risk for recurrence was worse when multiple risk factors were present(31).

\section{Conclusion}

In patients with stage IA EEC, PPC is an independent risk factor for recurrence. Adjuvant chemotherapy was not recommended for all stage IA EEC patients with PPC. However, by analyzing the cancer type, the presence of a population with a higher risk for recurrence was confirmed. It is therefore necessary to investigate the efficacy of adjuvant chemotherapy in patients with early stage EEC having risk factors for recurrence, especially those with many factors.

\section{Declarations}

\section{Acknowledgments}

We would like to thank Editage (www.editage.com) for English language editing.

\section{Disclosures}

The authors declare no conflicts of interest. 


\section{Financial Support}

No specific funding was received for this study.

\section{Authors' contributions}

The Author Contributions in this research is as follows;

Motoko Kanno: Data Curation, formal analysis, writing, review and editing. Mayu Yunokawa: Conceptualization, Data Curation, formal analysis, Supervison, Validation, writing, review and editing, Makoto Nakabayashi and Makiko Omi: data curation and investigation, Yuko Sugiyama: Supervision and review, Nobuhiro Takeshima and Hiroyuki Kanao: Project administration and review

All authors critically revised the report, commented on drafts of the manuscript, and approved the final report.

The data that support the findings of this study are available from the corresponding author, [M.Y.], upon reasonable request.

\section{References}

1. Colombo, N. et al. ESMO-ESGO-ESTRO consensus conference on endometrial cancer: Diagnosis, treatment and follow-up. Radiother Oncol. 2015;117(3):559 - 81.

2. Ebina, Y. et al. Japan Society of Gynecologic Oncology guidelines 2013 for the treatment of uterine body neoplasms. Int J Clin Oncol. 21 (3), 419-434 (2016).

3. Werner, H. M. et al. Revision of FIGO surgical staging in 2009 for endometrial cancer validates to improve risk stratification. Gynecol Oncol. 125 (1), 103-108 (2012).

4. Pecorelli, S. Revised FIGO staging for carcinoma of the vulva, cervix, and endometrium. Int $J$ Gynaecol Obstet. 105 (2), 103-104 (2009).

5. Kim, H. S. \& Song, Y. S. International Federation of Gynecology and Obstetrics (FIGO) staging system revised: what should be considered critically for gynecologic cancer? J Gynecol Oncol. 20 (3), 135136 (2009).

6. Milgrom, S. A. et al. Positive peritoneal cytology is highly predictive of prognosis and relapse patterns in stage III (FIGO 2009) endometrial cancer. Gynecol Oncol. 130 (1), 49-53 (2013).

7. Garg, G. et al. Positive peritoneal cytology is an independent risk-factor in early stage endometrial cancer. Gynecol Oncol. 128 (1), 77-82 (2013).

8. Cetinkaya, K. \& Atalay, F. Peritoneal cytology in endometrial cancer. Tumori. 101 (6), 697-700 (2015). 
9. Kyrgiou, M., Chatterjee, J., Lyus, R., Amin, T. \& Ghaem-Maghami, S. The role of cytology and other prognostic factors in endometrial cancer. J Obstet Gynaecol. 33 (7), 729-734 (2013).

10. Shiozaki, T. et al. Does positive peritoneal cytology not affect the prognosis for stage I uterine endometrial cancer?: the remaining controversy and review of the literature. Int J Gynecol Cancer. 24 (3), 549-555 (2014).

11. Han, K. H. et al. Peritoneal cytology: a risk factor of recurrence for non-endometrioid endometrial cancer. Gynecol Oncol. 134 (2), 293-296 (2014).

12. Lee, B., Suh, D. H., Kim, K., No, J. H. \& Kim, Y. B. Influence of positive peritoneal cytology on prognostic factors and survival in early-stage endometrial cancer: a systematic review and metaanalysis. Jpn J Clin Oncol. 46 (8), 711-717 (2016).

13. Tanaka, K. et al. Histologic grade and peritoneal cytology as prognostic factors in type 1 endometrial cancer. Int J Clin Oncol. 22 (3), 533-540 (2017).

14. Matsuo, K. et al. Significance of abnormal peritoneal cytology on survival of women with stage I-II endometrioid endometrial cancer. Gynecol Oncol. 149 (2), 301-309 (2018).

15. Seagle, B. L., Alexander, A. L., Lantsman, T. \& Shahabi, S. Prognosis and treatment of positive peritoneal cytology in early endometrial cancer: matched cohort analyses from the National Cancer Database. Am J Obstet Gynecol. 218 (3), 329 e1- e15. (2018).

16. Wang, L., Li, L., Wu, M. \& Lang, J. The prognostic role of peritoneal cytology in stage IA endometrial endometrioid carcinomas. Curr Probl Cancer. 44 (2), 100514 (2020).

17. Scott, S. A., van der Zanden, C., Cai, E., McGahan, C. E. \& Kwon, J. S. Prognostic significance of peritoneal cytology in low-intermediate risk endometrial cancer. Gynecol Oncol. 145 (2), 262-268 (2017).

18. Kasamatsu, T. et al. Prognostic significance of positive peritoneal cytology in endometrial carcinoma confined to the uterus. Br J Cancer. 88 (2), 245-250 (2003).

19. Chang, Y. N., Zhang, Y., Wang, Y. J., Wang, L. P. \& Duan, H. Effect of hysteroscopy on the peritoneal dissemination of endometrial cancer cells: a meta-analysis. Fertil Steril. 96 (4), 957-961 (2011).

20. Takac, I. \& Zegura, B. Office hysteroscopy and the risk of microscopic extrauterine spread in endometrial cancer. Gynecol Oncol. 107 (1), 94-98 (2007).

21. Creasman, W. Revised FIGO staging for carcinoma of the endometrium. Int J Gynaecol Obstet. 105 (2), 109 (2009).

22. Kurman, R. J. International Agency for Research on C, World Health O. WHO classification of tumours of female reproductive organs (International Agency for Research on Cancer, Lyon, 2014).

23. Creutzberg, C. L. et al. Surgery and postoperative radiotherapy versus surgery alone for patients with stage-1 endometrial carcinoma: multicentre randomised trial. The Lancet. 355 (9213), 1404-1411 (2000).

24. Ward, K. K. et al. The risk of uterine malignancy is linearly associated with body mass index in a cohort of US women. Am J Obstet Gynecol. 209 (6), 5791-5795 (2013). 
25. Gao, M. et al. Chemotherapy as Adjuvant Treatment for Early Stage Endometrial Cancer With High Intermediate Risk Factors. Int J Gynecol Cancer. 28 (7), 1285-1289 (2018).

26. Kanda, Y. Investigation of the freely available easy-to-use software 'EZR' for medical statistics. Bone Marrow Transplant. 48 (3), 452-458 (2013).

27. Morice, P., Leary, A., Creutzberg, C., Abu-Rustum, N. \& Darai, E. Endometrial cancer. Lancet. 387 (10023), 1094-1108 (2016).

28. Qu, X. M. et al. The role of adjuvant therapy in stage IA serous and clear cell uterine cancer: A multiinstitutional pooled analysis. Gynecol Oncol. 149 (2), 283-290 (2018).

29. Tatebe, K., Hasan, Y. \& Son, C. H. Adjuvant vaginal brachytherapy and chemotherapy versus pelvic radiotherapy in early-stage endometrial cancer: Outcomes by risk factors. Gynecol Oncol. 155 (3), 429-435 (2019).

30. Donovan, E. et al. Outcomes of Adjuvant Therapy for Stage IA Serous Endometrial Cancer. Cureus. 10 (9), e3387 (2018).

31. Takahashi, K. et al. A novel prediction score for predicting the baseline risk of recurrence of stage I-II endometrial carcinoma. J Gynecol Oncol. 30 (1), e8 (2019).

\section{Tables}

\section{Table 1}

Patient, disease, and treatment characteristics of all the patients $(n=989)$ 


\begin{tabular}{lll}
\hline Variable & $\mathbf{N = 9 8 9}$ & (\%) \\
\hline Age years & & \\
Median (years) & 55 & \\
Range & $26-87$ & \\
Histological type & & \\
Type I & 820 & 82 \\
$\quad$ Endometrioid G1 & 573 & 63 \\
$\quad$ Endometrioid G2 & 234 & 26 \\
$\quad$ Mucinous & 3 & 0.3 \\
$\quad$ Mixed (G1, G2, mucinous) & 10 & 1.1 \\
Type II & 169 & 18 \\
$\quad$ Endometrioid G3 & 52 & 5.7 \\
$\quad$ Serous & 22 & 2.4 \\
Clear & 12 & 1.3 \\
Carcinosarcoma & 34 & 3.7 \\
$\quad$ Mixed (type II) & 49 & 5.4 \\
Peritoneal cytology & & \\
Positive & 135 & 14 \\
Negative & 854 & 86 \\
\hline
\end{tabular}

\section{Table 2}

Risk factors for recurrence of endometrial carcinoma stage IA (univariate and multivariate analysis) 


\begin{tabular}{|c|c|c|c|c|c|}
\hline Characteristic & $\mathbf{N}$ & $\begin{array}{l}\text { Univariate } \\
\text { HR (95\% CI) }\end{array}$ & P-value & $\begin{array}{l}\text { Multivariate } \\
\text { HR }(95 \% \text { CI })\end{array}$ & P-value \\
\hline $\begin{array}{l}\text { Age } \\
<60 \\
\geq 60\end{array}$ & $\begin{array}{l}677 \\
312\end{array}$ & ${ }^{1} 2.08(1.73-3.70)$ & 0.012 & $\frac{1}{1.60(0.87-2.93)}$ & 0.13 \\
\hline $\begin{array}{l}\text { BMI } \\
<25 \\
\geq 25\end{array}$ & $\begin{array}{l}717 \\
272\end{array}$ & $\begin{array}{l}1 \\
2.03(1.13-3.66)\end{array}$ & 0.017 & $\stackrel{1}{2.46(1.35-4.48)}$ & 0.003 \\
\hline $\begin{array}{l}\text { Tumor grade } \\
\text { G1 } \\
\text { G2 } \\
\text { G3 }\end{array}$ & $\begin{array}{r}573 \\
234 \\
52\end{array}$ & $\begin{array}{l}1 \\
5.28(2.37-11.7) \\
3.13(0.84-11.7)\end{array}$ & $\begin{array}{c}<0.001 \\
0.089\end{array}$ & $\begin{array}{l}1 \\
3.18(1.38-7.27)\end{array}$ & 0.006 \\
\hline $\begin{array}{l}\text { Histological type } \\
\text { Type I } \\
\text { Type II }\end{array}$ & $\begin{array}{l}820 \\
169\end{array}$ & $\frac{1}{3.83(2.14-6.81)}$ & $<0.001$ & $\frac{1}{3.07(1.62-5.79)}$ & $<0.001$ \\
\hline $\begin{array}{l}\text { Peritoneal cytology } \\
\text { negative } \\
\text { positive }\end{array}$ & $\begin{array}{l}854 \\
135\end{array}$ & $\begin{array}{l}1 \\
2.58(1.36-4.89)\end{array}$ & 0.003 & $\begin{array}{l}1 \\
2.08(1.05-4.10)\end{array}$ & 0.036 \\
\hline $\begin{array}{l}\text { Myometrial invasion } \\
\text { Only EM } \\
<50 \%\end{array}$ & $\begin{array}{l}433 \\
556\end{array}$ & $\stackrel{1}{2.62(1.33-5.16)}$ & 0.005 & $\frac{1}{2.18(1.05-4.53)}$ & 0.036 \\
\hline $\begin{array}{l}\text { LVSI } \\
\text { negative } \\
\text { positive }\end{array}$ & $\begin{array}{l}885 \\
104\end{array}$ & $\begin{array}{l}1 \\
2.65(1.35-5.21)\end{array}$ & 0.004 & $1.40(0.66-2.93)$ & 0.37 \\
\hline
\end{tabular}

BMI: body mass index; LVSI: lymphovascular space invasion; OR: odds ratio; CI: confidence interval. HR: Hazard ratio

\section{Table 3}

Patient characteristics for peritoneal cytology-positive stage IA endometrial carcinoma $(\mathrm{N}=135)$ 


\begin{tabular}{|c|c|c|c|}
\hline haracteristics & $\begin{array}{l}\text { Type I } \\
(\mathrm{N}=99)(\%)\end{array}$ & Type II $(\mathrm{N}=36)(\%)$ & p-value \\
\hline $\begin{array}{l}\text { ge }<60 \\
\geq 60\end{array}$ & $\begin{array}{l}86(87) \\
13(13)\end{array}$ & $\begin{array}{l}21(58) \\
15(42)\end{array}$ & $<0.001$ \\
\hline $\begin{array}{l}\overline{\mathrm{MI}}<25 \\
\geq 25\end{array}$ & $\begin{array}{l}71(72) \\
28(28)\end{array}$ & $\begin{array}{l}29(81) \\
7(19)\end{array}$ & 0.26 \\
\hline 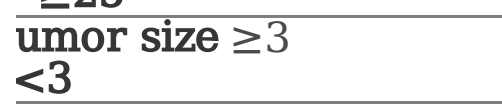 & $\begin{array}{l}590600 \\
40(40)\end{array}$ & $\begin{array}{l}19(53) \\
17(47)\end{array}$ & 0.55 \\
\hline $\begin{array}{l}\text { urgery } \\
\text { saparoscopy } \\
\text { _aparotomy }\end{array}$ & $\begin{array}{l}14(14) \\
85(85)\end{array}$ & $\begin{array}{l}3(8) \\
33(92)\end{array}$ & 0.56 \\
\hline $\begin{array}{l}\text { Iyometrial invasion } \\
\text { Jegative } \\
=50 \%\end{array}$ & $\begin{array}{l}31(31) \\
68(68)\end{array}$ & $\begin{array}{l}12(33) \\
24(67)\end{array}$ & 0.84 \\
\hline $\begin{array}{l}\text { VSI } \\
\text { 'resent } \\
\text { lbsent }\end{array}$ & $\begin{array}{l}15(15) \\
84(84)\end{array}$ & $\begin{array}{l}12(33) \\
24(67)\end{array}$ & 0.028 \\
\hline $\begin{array}{l}\text { ymphadenectomy } \\
\text { Jerformed } \\
\text { Jo performed }\end{array}$ & $\begin{array}{l}66(66) \\
33(33)\end{array}$ & $\begin{array}{l}26(72) \\
10(18)\end{array}$ & 0.003 \\
\hline $\begin{array}{l}\text { djuvant chemotherapy } \\
\text { With } \\
\text { Without }\end{array}$ & $\begin{array}{l}31(31) \\
68(69)\end{array}$ & $\begin{array}{l}27(75) \\
9(25)\end{array}$ & $<0.001$ \\
\hline $\begin{array}{l}\text { elapse } \\
\text { lo relapse }\end{array}$ & $\begin{array}{l}5(5) \\
94(95)\end{array}$ & $\begin{array}{l}8(32) \\
28(68)\end{array}$ & 0.006 \\
\hline
\end{tabular}

BMI: body mass index; LVSI: lymphovascular space invasion

\section{Table 4}

Risk factors for recurrence in peritoneal cytology-positive, endometrial carcinoma stage IA patients (univariate and multivariate analysis) 


\begin{tabular}{|c|c|c|c|c|c|}
\hline & $\mathbf{N}$ & $\begin{array}{l}\text { HR (95\% } \\
\text { CI) }\end{array}$ & $\begin{array}{l}\text { P- } \\
\text { value }\end{array}$ & $\begin{array}{l}\text { HR }(95 \% \\
\text { CI) }\end{array}$ & $\begin{array}{l}\text { P- } \\
\text { value }\end{array}$ \\
\hline $\begin{array}{l}\text { Age (range) } \\
<60 \\
\geq 60\end{array}$ & $\begin{array}{l}107 \\
28\end{array}$ & $\begin{array}{l}1 \\
3.96(1.31- \\
119)\end{array}$ & 0.014 & $\begin{array}{l}1 \\
2.86(0.85- \\
9.56)\end{array}$ & 0.088 \\
\hline $\begin{array}{l}\text { BMI } \\
<25 \\
\geq 25\end{array}$ & $\begin{array}{l}100 \\
35\end{array}$ & $\begin{array}{l}1 \\
2.28(0.71- \\
7.20)\end{array}$ & 0.160 & & \\
\hline $\begin{array}{l}\text { Grade } \\
\text { Endometrioid G1 } \\
\text { Endometrioid G2 } \\
\text { Endometrioid G3 }\end{array}$ & $\begin{array}{l}61 \\
36 \\
7\end{array}$ & $\begin{array}{l}1 \\
7.71(0.85- \\
69.6) \\
1.86(0.20- \\
17.1)\end{array}$ & $\begin{array}{l}0.068 \\
0.586\end{array}$ & & \\
\hline $\begin{array}{l}\text { Histology } \\
\text { Type I } \\
\text { Type II }\end{array}$ & $\begin{array}{l}99 \\
36\end{array}$ & $\begin{array}{l}1 \\
4.76(1.55- \\
14.5)\end{array}$ & 0.006 & $\begin{array}{l}1 \\
3.56(1.08- \\
11.6)\end{array}$ & 0.035 \\
\hline $\begin{array}{l}\text { Tumor size } \\
\geq 3 \mathrm{~cm}\end{array}$ & $\begin{array}{l}78 \\
57\end{array}$ & $\begin{array}{l}1 \\
0.44(0.14- \\
1.35)\end{array}$ & 0.153 & & \\
\hline $\begin{array}{l}\text { Surgery } \\
\text { Laparoscopy } \\
\text { Laparotomy }\end{array}$ & $\begin{array}{l}17 \\
118\end{array}$ & $\begin{array}{l}1 \\
0.38(0.10- \\
1.43)\end{array}$ & 0.152 & & \\
\hline $\begin{array}{l}\text { Myometrial invasion } \\
\text { negative } \\
<50 \%\end{array}$ & $\begin{array}{l}43 \\
92\end{array}$ & $\begin{array}{l}1 \\
0.67(0.21- \\
2.07)\end{array}$ & 0.488 & & \\
\hline $\begin{array}{l}\text { LVSI } \\
\text { present } \\
\text { absent }\end{array}$ & $\begin{array}{l}27 \\
108\end{array}$ & $\begin{array}{l}1 \\
0.71(0.16- \\
3.25)\end{array}$ & 0.669 & & \\
\hline $\begin{array}{l}\text { Lymphadenectomy } \\
\text { performed } \\
\text { no performed }\end{array}$ & $\begin{array}{l}92 \\
43\end{array}$ & $\begin{array}{l}1 \\
0.96(0.29- \\
3.18)\end{array}$ & 0.965 & & \\
\hline
\end{tabular}

BMI: body mass index; LVSI: lymphovascular space invasion

Figures 


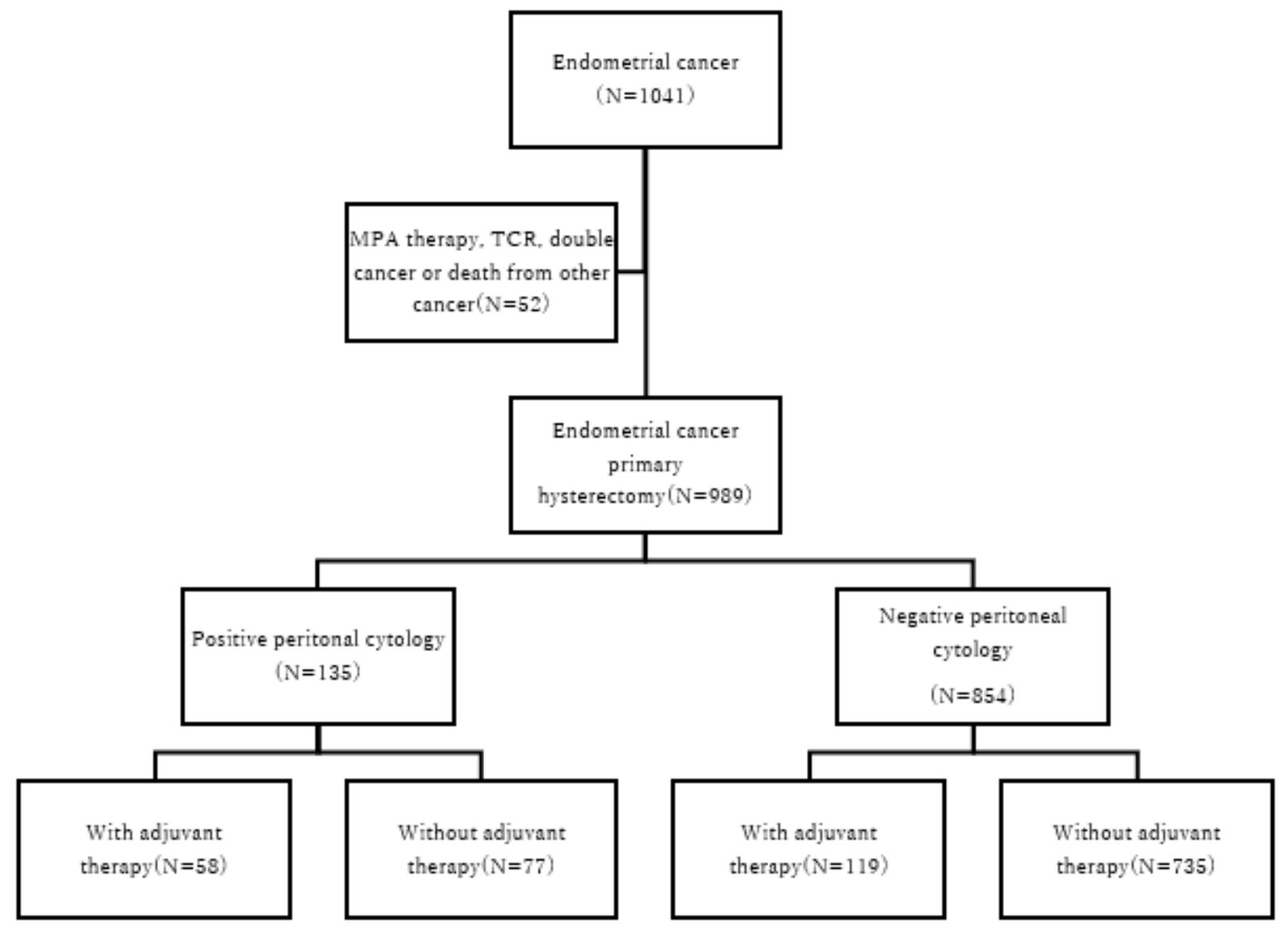

Figure 1

Flow chart of patient recruitment.
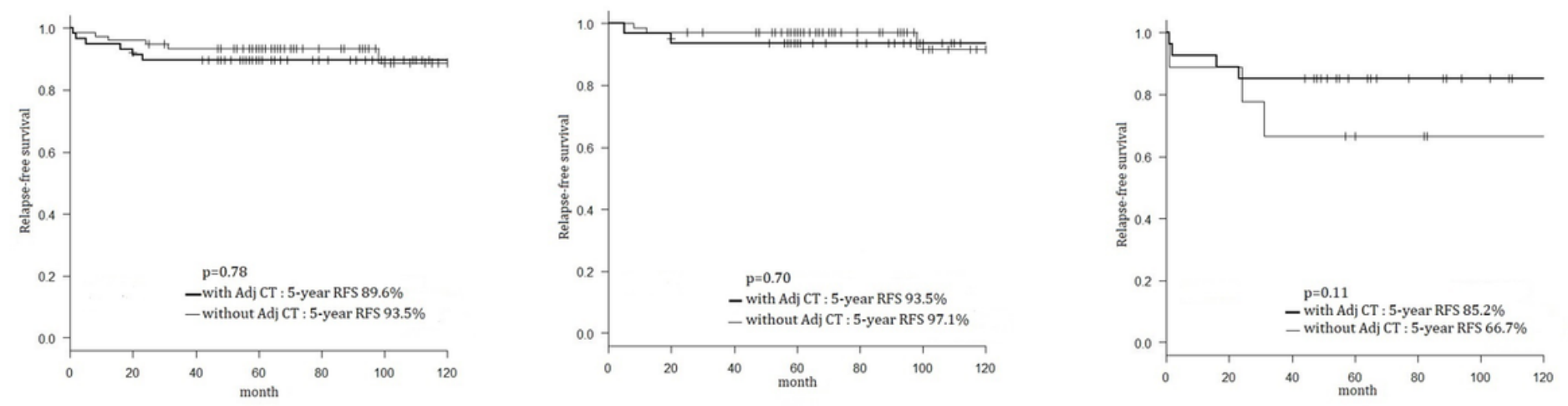

Figure 2

2-1. Kaplan-Meier curves for the relapse-free survival rates of PPC stage IA endometrial cancer patients with and without adjuvant chemotherapy PPC: positive peritoneal cytology, Adj CT: Adjuvant chemotherapy, RFS: Relapse-free survival. 2-2. Kaplan-Meier curves for the relapse-free survival rates of PPC stage IA endometrial cancer patients with and without adjuvant chemotherapy (Type I). PPC: positive peritoneal cytology, RFS: Relapse-free survival. 2-3. Kaplan-Meier curves for relapse-free survival rates of 
PPC stage IA endometrial cancer patients with and without adjuvant chemotherapy (type II). PPC: positive peritoneal cytology, RFS: Relapse-free survival.

\section{Supplementary Files}

This is a list of supplementary files associated with this preprint. Click to download.

- PPCIAsuppledata20201103.docx 